\title{
Cardiovascular disease among patients attending a specialist diabetes clinic in Jamaica
}

This article was published in the following Dove Press journal:

Research Reports in Clinical Cardiology

30 March 20II

Number of times this article has been viewed

\section{Trevor S Ferguson' \\ Marshall K Tulloch-Reid' \\ Novie OM Younger' \\ Rosemarie A Wright- \\ Pascoe $^{2}$ \\ Michael S Boyne' \\ Shelly R McFarlane' \\ Damian K Francis' \\ Rainford J Wilks'}

'Epidemiology Research Unit and Tropical Metabolism Research Unit, Tropical Medicine Research Institute,

${ }^{2}$ Department of Medicine,

The University of the West Indies,

Mona, Kingston, Jamaica
Correspondence: Trevor Ferguson Epidemiology Research Unit,

Tropical Medicine Research Institute, The University of the West Indies,

Mona, Kingston, Jamaica

Tel + | $876927247 \mid$

Fax +I 8769272984

Email trevor.ferguson02@uwimona.edu.jm
Background: This study aimed to estimate the prevalence of cardiovascular disease (CVD) among patients attending The University Hospital of the West Indies diabetes clinic and to examine the relationship between prevalent CVD and its risk factors.

Methods: We analyzed data from 174 patients selected from the University Hospital of the West Indies diabetes clinic using gender-stratified random sampling. An intervieweradministered questionnaire was used to obtain data on self-reported CVD (coronary heart disease [CHD], cerebrovascular disease, and peripheral vascular disease [PVD]), physical activity, alcohol consumption, and smoking. Trained nurses performed blood pressure and anthropometric measurements. A capillary blood sample was collected to measure glycosylated hemoglobin, and urine was tested for protein and microalbumin. Means and proportions for patient characteristics, CVD outcomes, and risk factors were calculated. Logistic regression was used to identify factors independently associated with CVD.

Results: Data from 129 women and 45 men (mean age $55.7 \pm 14.7$ years) were analyzed. The prevalence of any self-reported CVD (CHD, cerebrovascular disease, or PVD) was $34.5 \%$ (95\% confidence interval [CI] 27.4-41.6). PVD had the highest prevalence (25.9\%), compared with CHD (6.9\%) and cerebrovascular disease (16.1\%). There were no gender differences in the prevalence of CVD. Prevalence of CVD was higher among people $\geq 50$ years, and those with high blood pressure, central obesity, high total cholesterol, and duration of diabetes $\geq 20$ years. In multivariable models, duration of diabetes was the most consistent factor associated with CVD, odds ratio $1.41(95 \%$ CI $1.15-1.73, P=0.001)$ per five-year increment. Having blood pressure at the goal of $<130 / 80 \mathrm{mmHg}$ and at least three physical activity sessions/ week were associated with lower odds of CVD, odds ratios 0.42 (95\% CI $0.20-0.87, P=0.020$ ) and 0.37 (95\% CI 0.16-0.82, $P=0.014)$, respectively.

Conclusion: In this Jamaican setting, 35\% of patients with diabetes have at least one CVD. Odds of CVD increased with diabetes duration, while good blood pressure control and increased physical activity were ameliorating factors.

Keywords: cardiovascular disease, diabetes, Jamaica, diabetic complications, Caribbean

\section{Introduction}

Diabetes mellitus is an independent risk factor for cardiovascular disease (CVD) in both men and women, and has been designated as a CVD risk equivalent. ${ }^{1,2}$ Atherosclerotic vascular disease affecting the coronary, cerebral, and lower extremity vessels accounts for $80 \%$ of mortality and $75 \%$ of hospitalizations in persons with diabetes. ${ }^{3,4}$ CVD is also the largest contributor to the direct and indirect costs of diabetes mellitus. ${ }^{5}$ With the expected increase in the number of persons with diabetes in the coming decades, ${ }^{6,7}$ the challenge of CVD management in patients with diabetes 
will likely become an increasingly important problem for members of the health care team.

Despite being a major cause of morbidity and mortality in Jamaica and other Caribbean countries, ${ }^{8}$ there are few published data on CVD complications among persons with diabetes in the region. Early reports from the 1950s showed increased mortality among diabetic patients admitted with myocardial infarction in Jamaica, and data from the 1980s showed increased risk of coronary heart disease (CHD) among persons with diabetes in a Trinidadian cohort, ${ }^{8,9}$ but there are limited data available from studies conducted in the last 20 years. Recently, we have shown that almost $60 \%$ of persons admitted to The University Hospital of the West Indies with a diagnosis of diabetes also had some form of CVD recorded on their discharge summary, and that selfreported prevalence of stroke was higher among persons with diabetes compared with persons without diabetes, ${ }^{10,11}$ but there are no published reports on the overall prevalence of CVD among the diabetic population in Jamaica.

The aim of this study was to estimate the prevalence of CVD (CHD, cerebrovascular disease, and peripheral vascular disease [PVD]) among patients with diabetes attending The University Hospital of the West Indies diabetes clinic and to evaluate the relationship between CVD and its risk factors.

\section{Methods}

\section{Study design and sampling}

A cross-sectional survey was conducted among patients attending The University Hospital of the West Indies diabetes clinic, a specialist clinic staffed by endocrinologists or diabetes specialists and residents in The University Hospital of the West Indies internal medicine training program. Participants were evaluated between August 2009 and September 2010. The study was designed primarily to estimate the prevalence of diabetic foot complications. The sampling frame was compiled from a list of patients seen in the diabetes clinic in 2008. Participants were selected using gender-stratified random sampling, with a target sample size of 278 persons based on an estimated prevalence of foot complications of $12 \%{ }^{12}$ with a $5 \%$ margin of error at the $95 \%$ confidence level. The study was approved by The University Hospital of the West Indies, University of the West Indies, Faculty of Medical Sciences ethics committee.

\section{Recruitment}

Patients selected for the study were contacted by telephone and invited to participate. Written informed consent was obtained prior to data collection. Successful contact was made with 253 of the potential participants or their relatives. Of those contacted, 15 were reported to have died, 29 were unable to come in for evaluation or refused to participate, four reported that they did not have diabetes, one person had emigrated, and 16 persons missed appointments, resulting in a final recruited sample of 188 persons $(74.3 \%$ of contacted persons). Reasons for nonparticipation among those unable to come in for an appointment included being unable to get time off from work, difficulty with transport, and being too ill. The final sample for this analysis included 174 participants with data on CVD outcomes. This sample size was estimated to have a power of $79 \%$ to detect an $11 \%$ prevalence of stroke with a margin of error of $7 \%$, and a power of $76 \%$ to detect a $12 \%$ prevalence of $\mathrm{CHD}$ with a margin of error of $7 \%$. Estimated prevalence of stroke and CHD was based on previously published data from persons admitted with diabetes at The University Hospital of the West Indies. ${ }^{10}$

\section{Measurements and definitions}

All measurements were performed by trained staff. An interviewer-administered questionnaire was used to collect information on general health, diabetes control, and diabetes complications. Participants were asked if they had been told by a doctor or other health care professional that they had any of the following conditions: heart disease, stroke, transient ischemic attacks, or PVD. For heart disease, participants were asked to specify if they had been diagnosed with heart attack, angina, or heart failure. Participants who reported having heart attack or angina were classified as having CHD and those who reported stroke or transient ischemic attacks were classified as having cerebrovascular disease. For PVD, participants were asked if they had been told by a doctor that they had claudication pain, rest pain, or PVD; they were told that this referred to poor circulation in the arteries of the leg and not to leg swelling that resolves with leg elevation. Participants who reported a history of doctor-diagnosed PVD, claudication, or rest pain were classified as having PVD.

Body weight was measured to the nearest $0.1 \mathrm{~kg}$ using a portable digital scale, while height was measured to the nearest $0.1 \mathrm{~cm}$ using a portable stadiometer. Body mass index (BMI) was calculated as weight in kilograms divided by the square of height in meters, and participants were categorized as normal (BMI $<25 \mathrm{~kg} / \mathrm{m}^{2}$ ), overweight (BMI $\left.25.0-29.9 \mathrm{~kg} / \mathrm{m}^{2}\right)$, or obese $\left(\mathrm{BMI} \geq 30 \mathrm{~kg} / \mathrm{m}^{2}\right)$. Waist and hip circumference were obtained using a nonstretchable tape. 
Waist circumference was measured midway between the lowest rib and the iliac crest, and hip circumference at the level of the greater trochanter. Central obesity was defined as waist circumference $\geq 80 \mathrm{~cm}$ in women and $\geq 94 \mathrm{~cm}$ in men, as recommended by the International Diabetes Federation. ${ }^{13}$

Blood pressure was obtained using a mercury sphygmomanometer. Three blood pressure measurements were taken at one-minute intervals from the right arm after the participant had been seated for five minutes. ${ }^{14}$ The mean of the second and third blood pressure measurements was used in the analysis. Participants were classified as having high blood pressure if their systolic blood pressure was $\geq 130 \mathrm{mmHg}$, diastolic blood pressure $\geq 80 \mathrm{mmHg}$, or if they were on medication for high blood pressure. ${ }^{5}$

A capillary blood sample was collected for the measurement of glycosylated hemoglobin (HbA1c) using a point of care instrument (NycoCard ${ }^{\circledR}$ Reader II, Axis-Shield, Rodelokka, Oslo, Norway). This reader is certified by the National Glycohemoglobin Standardization Program US. ${ }^{15,16}$ Participants were classified as having good control ( $\mathrm{HbAlc}<7.0)$, inadequate control (HbA1c 7.0-8.9), or poor control (HbAlc $\geq 9.0$ ).

Urine protein excretion was measured on a freshly voided urine specimen using standard urine test strips. A colorimetric principle was used to obtain a semiquantitative estimate of urine protein excretion and coded as negative or positive. Positive test results were further classified as trace, $1+$, $2+$, or $3+$. Urine samples that were negative for protein were also tested for microalbumin using a semiquantitative test strip (Teco Diagnostics, Anaheim, CA). Participants were then classified as "no albuminuria" if negative on both urine dipstick and microalbumin tests, "microalbuminuria" if positive on the microalbumin test but negative on the standard urine dipstick test, or "gross proteinuria" if positive on the urine dipstick test.

Data on lipids (total cholesterol, high-density lipoprotein cholesterol [HDL], low-density lipoprotein cholesterol [LDL], and triglycerides) were abstracted from the patient's record using the last recorded values on the docket. Cutoff values were defined as follows: high total cholesterol, $\geq 5.2 \mathrm{mmol} / \mathrm{L}$; low HDL, $<1.0 \mathrm{mmol} / \mathrm{L}$ in men and $<1.3 \mathrm{mmol} / \mathrm{L}$ in women; high triglycerides, $>1.7 \mathrm{mmol} / \mathrm{L}$; and high $\mathrm{LDL}, \geq 2.6 \mathrm{mmol} / \mathrm{L}$.

\section{Statistical analysis}

Data were entered into an electronic database using EpiData 3.1, with range and consistency checks used to minimize data entry errors. Data analysis was done using Stata 10.1
(Stata Corporation, College Station, TX). Prevalence estimates for CVD complications in the entire sample and according to risk factor categories were obtained. Means and proportions were obtained for participant characteristics and CVD risk factors. Differences in proportions for categorical variables were compared using $\chi^{2}$ tests or Fisher's Exact test as appropriate, while the $t$-test was used for difference in means.

Multivariate logistic regression was used to obtain adjusted odds ratios (OR) for the presence any CVD, CHD, cerebrovascular disease, or PVD. Models for each outcome were created by sequentially adding variables to a base model containing gender and age (in five-year increments). The variables assessed were blood pressure (categorized as at goal $[<130 / 89 \mathrm{mmHg}]$ or not at goal), waist circumference (as a continuous variable), total cholesterol (normal/high/ unknown), low HDL (normal/high/unknown), smoking status, alcohol consumption, physical activity category, albuminuria category, diabetes control category, and diabetes duration (five-year increments). The effect of each variable on the model was determined using the likelihood ratio test. The Hosmer-Lemeshow test for goodness of fit was used to assess the final models. For the explanatory variables with missing values, we used imputation (based on participant's age and gender) when the variable was included as a continuous variable; alternatively, missing values were treated as a separate category when the variable was included in the model as a categorical variable.

\section{Results}

Of the 188 patients recruited, 174 persons (129 women, 45 men; mean age 56 years; mean diabetes duration 16 years) had available data on the CVD outcomes of interest. All the excluded participants were women, and except for a lower mean height $(157 \mathrm{~cm}$ versus $163 \mathrm{~cm})$, there were no significant differences between those excluded and the analyzed sample.

Summary statistics for the participant characteristics are presented in Table 1. Mean values for these characteristics were generally similar for men and women, except for BMI, total cholesterol, and HDL, which were higher in women, and height, which was higher in men.

Prevalence of estimates for overall CVD and its subtypes are shown in Table 2. The overall prevalence on any CVD (CHD, cerebrovascular disease, or PVD) was 34.5\% (95\% confidence interval [CI] 27.4-41.6). Of these persons with CVD, $67 \%$ reported one CVD, 27\% reported two CVDs, and $6 \%$ reported all three CVDs. PVD was the most common of 
Table I Characteristics of study participants with comparison of means for participant characteristics and cardiovascular risk factors by gender

\begin{tabular}{|c|c|c|c|}
\hline ristic & $\begin{array}{l}\text { Men } \\
\text { Mean } \pm \text { SD } \\
n=45\end{array}$ & $\begin{array}{l}\text { Women } \\
\text { Mean } \pm \text { SD } \\
n=129\end{array}$ & $\begin{array}{l}\text { Total } \\
\text { Mean } \pm \text { SD } \\
n=174\end{array}$ \\
\hline Age (years) & $56.5 \pm 14.8$ & $55.4 \pm 14.7$ & $55.7 \pm 14.7$ \\
\hline Height $(\mathrm{cm})^{* * *}$ & $172.4 \pm 5.6$ & $160.0 \pm 7.2$ & $163.2 \pm 8.7$ \\
\hline Weight & $81.0 \pm 16.2$ & $77.0 \pm 16.9$ & $78.0 \pm 16.8$ \\
\hline $\begin{array}{l}\text { Body mass } \\
\text { index** }\left(\mathrm{kg} / \mathrm{m}^{2}\right)\end{array}$ & $27.3 \pm 5.6$ & $30.1 \pm 6.2$ & $29.4 \pm 6.1$ \\
\hline $\begin{array}{l}\text { Waist } \\
\text { circumference }(\mathrm{cm})\end{array}$ & $94.2 \pm 16.1$ & $95.4 \pm 13.9$ & $95.1 \pm 14.5$ \\
\hline $\begin{array}{l}\text { Hip } \\
\text { circumference** }(\mathrm{cm})\end{array}$ & $100.9 \pm 9.5$ & $106.4 \pm 11.9$ & $104.9 \pm 11.6$ \\
\hline Waist/hip ratio & $0.93 \pm 0.09$ & $0.90 \pm 0.07$ & $0.90 \pm 0.08$ \\
\hline Systolic BP (mmHg) & $129.2 \pm 20.4$ & $128.5 \pm 22.3$ & $128.7 \pm 21.8$ \\
\hline Diastolic BP (mmHg) & $71.7 \pm 12.7$ & $70.7 \pm 13.2$ & $70.9 \pm 13.0$ \\
\hline Pulse rate (bpm) & $74 \pm 13$ & $78 \pm 14$ & $77 \pm 14$ \\
\hline $\begin{array}{l}\text { Total } \\
\text { cholesterol** (mmol/L) }\end{array}$ & $4.2 \pm 1.2$ & $5.1 \pm 1.4$ & $5.0 \pm 1.3$ \\
\hline $\begin{array}{l}\text { LDL } \\
\text { cholesterol (mmol/L) }\end{array}$ & $3.0 \pm 1.0$ & $3.3 \pm 1.2$ & $3.2 \pm 1.1$ \\
\hline $\begin{array}{l}\mathrm{HDL} \\
\text { cholesterol* (mmol/L) }\end{array}$ & $1.2 \pm 0.2$ & $1.3 \pm 0.3$ & $1.2 \pm 0.3$ \\
\hline Triglycerides (mmol/L) & $1.21 \pm 0.9$ & $\mathrm{I} .4 \pm \mathrm{I} . \mathrm{I}$ & $1.3 \pm 1.0$ \\
\hline $\mathrm{HbAlc}(\%)$ & $7.3 \pm 1.6$ & $7.8 \pm 2.0$ & $7.6 \pm 1.9$ \\
\hline Duration of DM (years) & $18.0 \pm 13.2$ & $15.9 \pm 10.0$ & $16.4 \pm 10.9$ \\
\hline Age at diagnosis (years) & $38.9 \pm 15.1$ & $40.0 \pm 12.8$ & $39.7 \pm 13.4$ \\
\hline
\end{tabular}

Notes: $* P<0.05 ; * * P<0.01 ; * * * P<0.001 ; P$ values are for male/female differences. Data for height, weight, BMl, waist circumference, hip circumference, and waist/hip ratio include six imputed values. Imputed values were also used for total cholesterol (2I), LDL (34), HDL (36), triglycerides (2I), duration of diabetes (26), and age at diagnosis (26).

Abbreviations: bpm, beats per minute; LDL, low-density lipoprotein; HDL, high-density lipoprotein; DM, diabetes mellitus; HbAlc, glycosylated hemoglobin; BMI, body mass index; BP, blood pressure; SD, standard deviation.

the three CVDs, with a prevalence of $25.9 \%$ compared with $16.1 \%$ for cerebrovascular disease and $6.9 \%$ for CHD. There were no statistically significant gender differences in the prevalence of overall CVD or its subtypes, but a higher proportion of women reported cerebrovascular disease and a higher proportion of men reported CHD. None of the men reported a history of angina pectoris, and a higher proportion of women reported transient ischemic attacks.

Table 3 shows the percentage of participants with various CVD risk factors within and across gender categories. The majority of participants (68\%) were 50 years or older, $72 \%$ had high blood pressure, 34\% were overweight, and 39\% were obese. Prevalence of obesity was higher in women compared with men (43\% versus $27 \%$ ). Women also had a higher prevalence of central obesity ( $85 \%$ versus $42 \%$ ), high total cholesterol ( $83 \%$ versus 53\%), and low HDL cholesterol (47\% versus $20 \%$ ). More men reported a history of past or current tobacco smoking (64\% versus 13\%). Only two participants gave a history of current smoking. There was no significant difference in current alcohol use, but past alcohol use was higher in men compared with women (51\% versus $23 \%$ ). A majority of patients (53\%) reported engaging in work-related or leisure time physical activity of at least 20 minutes' duration on three or more days per week. Forty-three percent of participants had good diabetes control (HbAlc $<7.0 \%$ ) while more women than men had poor control (26\% versus $11 \%)$.

Table 4 shows the prevalence of overall CVD and its subtypes within categories of selected risk factors. Patterns were generally similar for all CVD subtypes. Factors associated with increased prevalence of CVD included the following: older age ( $42 \%$ in persons $\geq 50$ years compared with $18 \%$ in those $<50$ years); hypertension ( $41 \%$ versus $18 \%$ ); central obesity ( $39 \%$ versus $23 \%$ ); and diabetes duration ( $62 \%$ among those with diabetes mellitus for $\geq 20$ years versus $23 \%$ for those with diabetes duration $<20$ years). Participants with blood pressure at the recommended goal of $<130 / 80 \mathrm{mmHg}$ and those who engaged in work-related or leisure physical activity for three or more days per week

Table 2 Prevalence of overall cardiovascular disease and subtypes among study participants by gender

\begin{tabular}{|c|c|c|c|}
\hline Characteristic & $\begin{array}{l}\text { Men \% }(95 \% \mathrm{Cl}) \\
\mathrm{n}=45\end{array}$ & $\begin{array}{l}\text { Women \% }(95 \% \mathrm{Cl}) \\
n=129\end{array}$ & $\begin{array}{l}\text { Total \% }(95 \% \mathrm{Cl}) \\
\mathrm{n}=\mathrm{I} 74\end{array}$ \\
\hline Any cardiovascular disease & $37.8(23.4-52.2)$ & $33.3(25 .|-4| .6)$ & $34.5(27.4-41.6)$ \\
\hline Coronary heart disease & $4.4(0-10.6)$ & $7.8(3.1-12.4)$ & $6.9(3.1-10.7)$ \\
\hline Angina & - & $5.4(1.5-9.4)$ & $4.0(1.1-7.0)$ \\
\hline Heart attack & $4.4(0-10.6)$ & $2.3(0-5.0)$ & $2.9(0.4-5.4)$ \\
\hline Cerebrovascular disease & I3.3 (3.2-23.4) & I7.I (I0.5-23.6) & I6.I (I0.6-21.6) \\
\hline Transient ischemic attack & $2.2(0-6.6)$ & $7.8(3.1-12.4)$ & $6.3(2.7-10.0)$ \\
\hline Stroke & II.I (I.7-20.5) & $9.3(4.2-14.4)$ & $9.8(5.3-14.2)$ \\
\hline Peripheral vascular disease & $31.1(17.3-44.9)$ & $24.0(\mid 6.6-31.5)$ & $25.9(19.3-32.4)$ \\
\hline
\end{tabular}

Notes: Any cardiovascular disease includes a combination of coronary heart disease, cerebrovascular disease, and peripheral vascular disease. Coronary heart disease includes angina and heart attack, and cerebrovascular disease includes stroke and transient ischemic attacks.

Abbreviation: $\mathrm{Cl}$, confidence interval. 
Table 3 Percentage of participants in cardiovascular disease or diabetes risk categories by gender

\begin{tabular}{|c|c|c|c|}
\hline Characteristic & $\begin{array}{l}\text { Men \% (SE) } \\
n=45\end{array}$ & $\begin{array}{l}\text { Women \% (SE) } \\
n=129\end{array}$ & $\begin{array}{l}\text { Total \% (SE) } \\
n=174\end{array}$ \\
\hline \multicolumn{4}{|l|}{ Age category } \\
\hline$<50$ years & $28.9(6.8)$ & $32.6(4.1)$ & $31.6(3.5)$ \\
\hline$\geq 50$ years and older & $7 I . I(6.8)$ & $67.4(4.1)$ & $68.4(3.5)$ \\
\hline High blood pressure ( $\geq 130 / 80 \mathrm{mmHg}$ or on medication) & $71.1(6.8)$ & 72.I (4.0) & $71.8(3.4)$ \\
\hline Blood pressure not at goal ( $\geq 130 / 80 \mathrm{mmHg}$ with or without medication) & $5 I . I(7.5)$ & $46.5(4.4)$ & $47.7(3.8)$ \\
\hline \multicolumn{4}{|l|}{ BMI category } \\
\hline Overweight (BMI 25-29.9) & $35.6(7.2)$ & $33.3(4.2)$ & $33.9(3.6)$ \\
\hline Obese $(\mathrm{BMI} \geq 30)^{*}$ & $26.7(6.7)$ & $42.6(4.4)$ & $38.5(3.7)$ \\
\hline Central obesity*** (WC $>80 \mathrm{~cm}$ in women; $>94 \mathrm{~cm}$ in men) & $42.2(7.4)$ & $84.5(3.2)$ & $73.6(3.4)$ \\
\hline \multicolumn{4}{|l|}{ Lipid profile } \\
\hline High total cholesterol*** ( $\geq 5.2 \mathrm{mmol} / \mathrm{L}$ or on medication) & $53.3(7.5)$ & $82.9(3.3)$ & $75.3(3.3)$ \\
\hline High LDL-C for diabetes ( $\geq 2.6 \mathrm{mmol} / \mathrm{L}$ with or without medication) & $48.9(7.5)$ & $54.3(4.4)$ & $52.9(3.8)$ \\
\hline Low HDL-C*** $(<1.0 \mathrm{mmol} / \mathrm{L}$ in men or $<1.3 \mathrm{mmol} / \mathrm{L}$ in women $)$ & $20.0(6.0)$ & $47.3(4.4)$ & $40.2(3.7)$ \\
\hline High triglycerides ( $\geq 1.7 \mathrm{mmol} / \mathrm{L})$ & $15.6(5.5)$ & $20.9(3.6)$ & $19.5(3.0)$ \\
\hline \multicolumn{4}{|l|}{ Smoking status } \\
\hline Never smoked tobacco*** & $35.6(7.2)$ & $85.3(3.1)$ & $72.4(3.4)$ \\
\hline Past or current smoker*** & $64.4(7.2)$ & $13.2(3.0)$ & $26.4(3.4)$ \\
\hline \multicolumn{4}{|l|}{ Alcohol consumption } \\
\hline Never drank alcohol*** & $37.8(7.3)$ & $69.7(4.1)$ & $61.5(3.7)$ \\
\hline Past alcohol use ${ }^{* *}$ & $51.1(7.5)$ & $23.3(3.7)$ & $30.5(3.5)$ \\
\hline Current alcohol use & II.I (4.7) & $7.0(2.3)$ & $8.0(2.1)$ \\
\hline \multicolumn{4}{|l|}{ Physical activity category } \\
\hline No significant exercise & $20.0(6.0)$ & $28.7(4.0)$ & $26.4(3.4)$ \\
\hline Exercises two or less times per week & $22.2(6.3)$ & $17.8(3.4)$ & $19.0(3.0)$ \\
\hline Exercises three or more times per week & $57.8(7.4)$ & $51.9(4.4)$ & $53.4(3.8)$ \\
\hline \multicolumn{4}{|l|}{ Albuminuria } \\
\hline Microalbuminuria & $13.3(5.1)$ & I7.I (3.3) & I6.I (2.8) \\
\hline Gross proteinuria & $55.6(7.4)$ & $58.1(4.3)$ & $57.5(3.8)$ \\
\hline Current insulin treatment & $68.9(7.0)$ & $69.0(4.1)$ & $69.0(3.5)$ \\
\hline \multicolumn{4}{|l|}{ Diabetes control } \\
\hline Good (HbAlc < 7.0\%) & $44.4(7.5)$ & $42.6(4.4)$ & $43.1(3.8)$ \\
\hline Inadequate (HbAlc 7\%-8.9\%) & $44.4(7.5)$ & $31.8(4.1)$ & $35.1(3.6)$ \\
\hline Poor (HbAlc $\geq 9 \%)^{*}$ & II.I (4.7) & $25.6(3.9)$ & $21.8(3.1)$ \\
\hline
\end{tabular}

Notes: $* P<0.05$; **P $<0.01$; *** $P<0.001$; $P$ values are for male/female differences. For proportion calculations, participants with missing values treated as separate category hence denominator for all proportions are as per column total.

Abbreviations: LDL, low-density lipoprotein; HDL, high-density lipoprotein; WC, waist circumference; HbAlc, glycosylated hemoglobin; BMI, body mass index; SE, standard error.

were less likely to have CVD. The prevalence estimate for CVD was $23 \%$ among persons with blood pressure at goal compared with $47 \%$ among persons whose blood pressure was not at goal. Similarly, prevalence of CVD among persons who reported physical activity three or more times per week was $26 \%$ compared with $39 \%$ among those reporting physical activity two or fewer times per week, and 50\% among those reporting no significant work-related or leisure physical activity.

In order to describe the relationship between clustering of CVD risk factors within individuals and the prevalence of CVD, we created a variable for the number of risk factors per individual, using the risk components of the United Kingdom Prospective Diabetes Study Risk Engine. ${ }^{17}$ We included all components, except for atrial fibrillation, for which we had no data. However, we used the components as categorical variables to facilitate a count of the number of risk factors per individual. Components counted in the risk score were age $\geq 50$ years, male gender, diabetes duration of $\geq 20$ years, past or current smoking, poor glycemic control $(\mathrm{HbAlc} \geq 9.0 \%$ ), high total cholesterol, low HDL cholesterol, and blood pressure $\geq 130 / 80 \mathrm{mmHg}$. The distribution of number of risk factors in gender categories is shown in Figure 1. Most participants $(66 \%)$ had three or four risk factors, but a higher proportion of men had 5-7 risk factors $(P<0.001$ for difference between males and females). Figure 2 shows the prevalence of overall CVD by number of risk factors. Prevalence increased from $29 \%$ among persons with one or two risk 
Table 4 Prevalence of cardivoscular disease by risk factor categories

\begin{tabular}{|c|c|c|c|c|}
\hline Characteristic & Any CVD \% & CHD \% & Stroke/TIA \% & PVD \% \\
\hline \multicolumn{5}{|l|}{ Age category } \\
\hline$<50$ years & 18.2 & 1.8 & 3.6 & 16.4 \\
\hline$\geq 50$ years & $42.0 * * *$ & $9.2^{*}$ & $21.8^{* * *}$ & $30.3^{*}$ \\
\hline \multicolumn{5}{|l|}{ Blood pressure } \\
\hline Not hypertensive & 18.4 & 2.0 & 8.1 & 14.3 \\
\hline \multicolumn{5}{|l|}{$(<130 / 80 \mathrm{mmHg}$ without medication) } \\
\hline Hypertensive ( $\geq 130 / 80 \mathrm{mmHg}$ or on medication) & $40.8^{* *}$ & $8.8^{*}$ & $19.2 *$ & $30.4^{*}$ \\
\hline \multicolumn{5}{|l|}{ Blood pressure goal } \\
\hline Not at goal $(\geq 130 / 80 \mathrm{mmHg})$ & 47.0 & 9.6 & 22.9 & 34.9 \\
\hline At goal $(<130 / 80 \mathrm{mmHg})$ & $23.1 * * *$ & 4.4 & $9.9 *$ & $17.6 * *$ \\
\hline \multicolumn{5}{|l|}{ BMI category } \\
\hline Not overweight (BMI < 25.0) & 21.4 & - & 2.4 & 19.0 \\
\hline Overweight (BMI 25-29.9) & 37.3 & 8.5 & 20.3 & 22.0 \\
\hline Obese $(\mathrm{BMI} \geq 30)$ & 41.8 & $9.0^{*}$ & $21.0^{* * *}$ & 34.3 \\
\hline \multicolumn{5}{|c|}{ Central obesity (WC $>80 \mathrm{~cm}$ in women; $>94 \mathrm{~cm}$ in men) } \\
\hline No central obesity & 22.5 & - & 7.5 & 17.5 \\
\hline Central obesity present & $39.1 *$ & $8.6 * * *$ & $18.8^{*}$ & 28.9 \\
\hline \multicolumn{5}{|c|}{ High total cholesterol ( $\geq 5.2 \mathrm{mmol} / \mathrm{L}$ or on medication) } \\
\hline Absent & 21.9 & 3.1 & 6.3 & 15.6 \\
\hline Present & $38.9 *$ & 7.6 & $19.1 *$ & 29.0 \\
\hline \multicolumn{5}{|c|}{ High LDL-C for diabetes ( $\geq 2.6 \mathrm{mmol} / \mathrm{L}$ with or without medication) } \\
\hline Absent & 39.6 & 5.4 & 12.5 & 29.2 \\
\hline Present & 32.6 & 8.3 & 15.2 & 26.1 \\
\hline \multicolumn{5}{|c|}{ Low HDL-C $(<1.0 \mathrm{mmol} / \mathrm{L}$ in $\mathrm{men}$ or $<1.3 \mathrm{mmol} / \mathrm{L}$ in women $)$} \\
\hline Absent & 38.2 & 4.4 & 11.8 & 32.4 \\
\hline Present & 31.4 & 7.1 & 15.7 & 21.4 \\
\hline \multicolumn{5}{|l|}{ High triglycerides ( $\geq 1.7 \mathrm{mmol} / \mathrm{L})$} \\
\hline Absent & 31.9 & 5.8 & 11.8 & 24.3 \\
\hline Present & 38.2 & 5.8 & 20.6 & 29.4 \\
\hline \multicolumn{5}{|l|}{ Smoking status } \\
\hline Never smoked tobacco & 31.0 & 7.9 & 14.3 & 22.2 \\
\hline Past or current smoker & 43.5 & 4.3 & 19.6 & 34.8 \\
\hline \multicolumn{5}{|l|}{ Alcohol consumption } \\
\hline Never drank alcohol & 36.4 & 9.3 & 17.8 & 26.2 \\
\hline Past alcohol use & 35.8 & 1.8 & I5.I & 28.3 \\
\hline Current alcohol use & 14.3 & 7.1 & 7.1 & 14.3 \\
\hline \multicolumn{5}{|l|}{ Physical activity level } \\
\hline No significant exercise & 50.0 & 13.0 & 26.1 & 37.0 \\
\hline Exercises two or less times per week & 39.4 & 3.0 & 15.2 & 33.3 \\
\hline Exercises three or more times per week & $25.8^{*}$ & 5.3 & 11.8 & $18.3^{*}$ \\
\hline \multicolumn{5}{|l|}{ Albuminuria } \\
\hline No albuminuria & 14.3 & - & 7.1 & 7.1 \\
\hline Microalbuminuria & 28.6 & 10.7 & 21.4 & 14.3 \\
\hline Gross proteinuria & 39.0 & $7.0 * *$ & 15.0 & $30.0 *$ \\
\hline \multicolumn{5}{|l|}{ Diabetes control } \\
\hline Good (HbAlc < 7.0\%) & 34.7 & 6.7 & 18.7 & 26.7 \\
\hline Inadequate (HbAlc 7\%-8.9\%) & 34.4 & 6.6 & 16.4 & 27.9 \\
\hline Poor (HbAlc $\geq 9 \%)$ & 34.2 & 7.9 & 10.5 & 21.1 \\
\hline \multicolumn{5}{|l|}{ Diabetes duration } \\
\hline Less than 20 years & 23.3 & 2.9 & 7.8 & 16.5 \\
\hline 20 years or more & $62.2^{* * *}$ & $15.6^{*}$ & $35.6 * * *$ & $48.9 * * *$ \\
\hline
\end{tabular}

Notes: $* P<0.05$; ** $P<0.01$; ***P $<0.001$; $P$ values are for comparison across $C V D$ risk factor categories.

Abbreviations: LDL, low-density lipoprotein; HDL, high-density lipoprotein; WC, waist circumference; CVD, cardiovascular disease; CHD, coronary heart disease; TIA, transient ischemic attacks; PVD, peripheral vascular disease; HBAIc, glycosylated hemoglobin. 


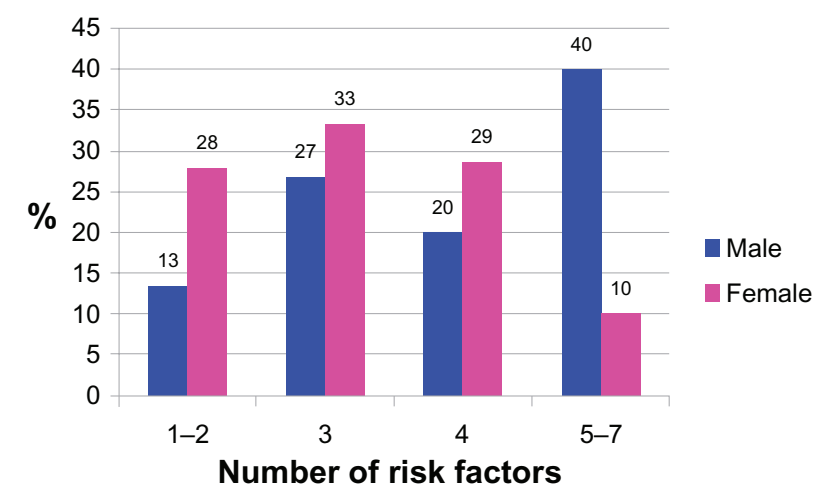

Figure I Percentage of participants with United Kingdom Prospective Diabetes Study Risk Engine components.

Note: $P \leq 0.001$ (male/female difference in proportions for entire distribution).

factors to $48 \%$ among persons with 5-7 risk factors $(P=0.05$ for association and $P=0.019$ for trend).

The results for the multivariable analyses are shown in Table 5. Separate models were created for any CVD (CHD, cerebrovascular disease, or PVD), CHD, cerebrovascular disease, and PVD. Diabetes duration was consistently associated with CVD in all the models, with a $31 \%-41 \%$ increase in the odds for CVD for each five-year increase in diabetes duration. OR were: any CVD 1.41, $P=0.001$; CHD 1.34, $P=0.034$; cerebrovascular disease $1.31, P=0.021$; and PVD $1.39, P=0.002$. Blood pressure $<130 / 80 \mathrm{mmHg}$ was associated with a $29 \%-58 \%$ reduction in the odds of CVD, but achieved statistical significance only in the model for any CVD. Physical activity was also associated with reduced odds of any CVD (OR $0.37, P=0.014$ for three or more physical activity sessions per week compared with no significant physical activity), while higher waist circumference was associated with increased odds of CVD in models for $\mathrm{CHD}$ and cerebrovascular disease (OR 1.05, $P=0.043$ per $1 \mathrm{~cm}$ difference in waist circumference for CHD and 1.04,

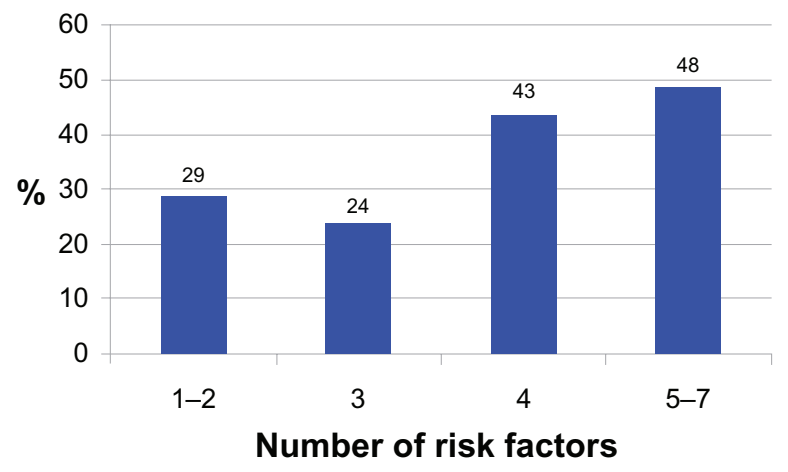

Figure 2 Proportion of participants with overall cardiovascular disease by number of risk factors.

Notes: $P=0.050 ; P$ (trend) $=0.019$. $P$-values are for the entire distribution.
$P=0.031$ per $1 \mathrm{~cm}$ difference in waist circumference for cerebrovascular disease).

\section{Discussion}

In this study we found that $35 \%$ of patients with diabetes attending a specialist diabetes clinic had at least one major CVD. Although PVD had the highest prevalence (26\%) of the three categories of CVD studied, a significant proportion of participants reported CHD (7\%) and cerebrovascular disease (16\%). There were no gender differences in the prevalence of CVD in this study. Prevalence of CVD was higher among persons $\geq 50$ years, those with high blood pressure, central obesity, or high total cholesterol, and among persons with a diabetes duration $\geq 20$ years. In multivariable models, duration of diabetes was the most consistent factor associated with prevalent CVD, while having a blood pressure at goal of $<130 / 80 \mathrm{mmHg}$ and engaging in three or more physical activity sessions per week were associated with lower odds of CVD.

Few studies have reported prevalence estimates for CVD in patients with diabetes. However, the estimates found in our study are similar to self-reported CVD prevalence in persons with diabetes in the US where the prevalence of any CVD was $32.5 \%$ among persons $\geq 35$ years in $2005 .{ }^{18}$ In that study, prevalence of CVD was lower in blacks (27.1\%) compared with whites (33.7\%). In another study from Catalonia in Spain, the prevalence of CVD (CHD, stroke, or PVD) among persons with diabetes obtained from patient interviews and medical records was $22.0 \% .{ }^{19}$ These studies confirm the high prevalence of CVD in patients with diabetes, and support the recommendations for intensive CVD prevention strategies in patients with diabetes, by the American Diabetes Association and National Cholesterol Education Programme. ${ }^{1,5}$

Prevalence of heart attack and stroke in this study $(2.9 \%$ and $9.8 \%$, respectively) was much higher than seen in the general Jamaican population $(0.7 \%$ for heart attacks, $1.4 \%$ for stroke) but was similar to rates among persons with diabetes selected from the general population $(1.8 \%$ for heart attacks and $7.2 \%$ for strokes). ${ }^{11}$ This suggests that, although the patients were selected from a specialist diabetes clinic, the CVD experience may not be significantly different from a population-based sample of persons with diabetes.

The association between CVD risk factors and CVD events in this study were, in the main, consistent with the literature, and were similar to the findings in the North Catalonia Diabetes Study. ${ }^{19}$ The absence of any association with glycemic control is consistent with other studies which 
Table 5 Factors associated with major cardiovascular disease in multivariable logistic regression models

\begin{tabular}{|c|c|c|c|}
\hline Variable & Odds ratio & $95 \% \mathrm{Cl}$ & $P$ value \\
\hline \multicolumn{4}{|l|}{ Any cardiovascular disease (CHD, stroke/TIA, PVD) } \\
\hline Men (versus women) & 1.13 & $0.5-2.5$ & 0.769 \\
\hline Age (per 5-year increment) & 0.99 & $0.86-1.15$ & 0.938 \\
\hline Duration of diabetes (per 5-year increment) & 1.41 & $1.15-1.73$ & 0.001 \\
\hline Blood pressure at goal ( $<130 / 80 \mathrm{mmHg}$ versus $\geq 130 / 80 \mathrm{mmHg}$ ) & 0.42 & $0.20-0.87$ & 0.020 \\
\hline I-2 physical activity sessions/week (versus no significant physical activity) & 0.61 & $0.22-1.67$ & 0.337 \\
\hline$\geq 3$ physical activity sessions/week (versus no significant physical activity) & 0.37 & $0.16-0.82$ & 0.014 \\
\hline \multicolumn{4}{|l|}{ Coronary heart disease (heart attack or angina) } \\
\hline Men (versus women) & 0.36 & $0.06-2.02$ & 0.244 \\
\hline Duration of diabetes (per 5-year increment) & 1.34 & $1.02-1.76$ & 0.034 \\
\hline Blood pressure at goal $(<130 / 80 \mathrm{mmHg}$ versus $\geq 130 / 80 \mathrm{mmHg}$ ) & 0.71 & $0.19-2.68$ & 0.613 \\
\hline Waist circumference (per cm) & 1.05 & $1.00-1.10$ & 0.043 \\
\hline \multicolumn{4}{|l|}{ Cerebrovascular disease (stroke or TIA) } \\
\hline Men (versus women) & 0.49 & $0.16-|.5|$ & 0.213 \\
\hline Age (per 5-year increment) & 1.09 & $0.89-1.34$ & 0.407 \\
\hline Duration of diabetes (per 5 -year increment) & 1.31 & $1.04-1.65$ & 0.021 \\
\hline Blood pressure at goal $(<130 / 80 \mathrm{mmHg}$ versus $\geq 130 / 80 \mathrm{mmHg}$ ) & 0.59 & $0.23-1.50$ & 0.265 \\
\hline Waist circumference (per cm) & 1.04 & $1.00-1.07$ & 0.031 \\
\hline Low HDL cholesterol (versus normal HDL) & 1.38 & $0.48-3.97$ & 0.546 \\
\hline HDL unknown (versus normal HDL) & 4.67 & $1.40-15.68$ & 0.012 \\
\hline \multicolumn{4}{|l|}{ Peripheral vascular disease } \\
\hline Men (versus women) & 1.33 & $0.57-3.12$ & 0.514 \\
\hline Age (per 5-year increment) & 0.96 & $0.81-1.13$ & 0.606 \\
\hline Duration of diabetes (per 5 -year increment) & 1.39 & $1.12-1.72$ & 0.002 \\
\hline Blood pressure at goal $(<130 / 80 \mathrm{mmHg}$ versus $\geq 130 / 80 \mathrm{mmHg}$ ) & 0.55 & $0.25-1.21$ & 0.137 \\
\hline Waist circumference (per cm) & 1.02 & $0.99-1.05$ & 0.139 \\
\hline I-2 physical activity sessions/week (versus no significant physical activity) & 0.93 & $0.32-2.67$ & 0.893 \\
\hline$\geq 3$ physical activity sessions/week (versus no significant physical activity) & 0.45 & $0.19-1.08$ & 0.074 \\
\hline
\end{tabular}

Abbreviations: $\mathrm{Cl}$, confidence interval; TIA, transient ischemic attack; $\mathrm{CHD}$, coronary heart disease; PVD, peripheral vascular disease; HDL, high-density lipoprotein.

have failed to show that tight glycemic control reduces macrovascular complications of diabetes and may increase the risk of mortality, ${ }^{20,21}$ although previous epidemiological studies had shown higher CVD risk among persons with higher $\mathrm{HbA1c} .{ }^{22}$

The use of self-reports to assess CVD outcome status may be considered a limitation of this study. Although ascertainment of outcome status by use of medical records or direct measurement may have been advantageous, the use of self-reporting is a generally accepted means of outcome assessment, and has been shown to have fairly good validity in epidemiological studies. ${ }^{23-27}$ For example, Okura et al found that self-reported data from questionnaires had a sensitivity of $90 \%$ for heart attack and $78 \%$ for stroke, while specificity was $98 \%$ for heart attack and $99 \%$ for stroke. ${ }^{25} \mathrm{In}$ another study, researchers from Australia were able to demonstrate good agreement between prevalence of diabetic foot disease, including PVD, obtained from questionnaires and estimates from clinical examination or medical records. ${ }^{28} \mathrm{We}$ therefore believe that the estimates presented for this study are plausible.
While we were able to show associations between CVD and a number of risk factors, we are unable to infer causality because of the cross-sectional design of the study. For instance, the association between CVD prevalence and blood pressure may be a result of more aggressive blood pressure control in the setting of CVD. CVD may also affect an individual's ability to exercise, and these patients might report lower levels of physical activity. However, the associations found are consistent with the general medical literature which has previously established temporal relationship in prospective studies, thus giving support to a likely causal association. . $^{29,30}$

Missing data for some study participants is another potential limitation of the study. However, we note that only a small proportion had missing data on CVD outcome, and while these were all women, they were similar to the analyzed sample, except for lower mean height. Where participants had missing data for explanatory variables, we used imputation or the creation of a separate category to facilitate inclusion in analyses. It is therefore unlikely that missing data would have influenced any of the findings from the 
study. We also acknowledge that the number of men in this study was relatively small, but the proportion of men in the sample $(24 \%)$ was consistent with the proportion of men registered in the clinic (29\%). The female predominance in the clinic is consistent with the higher prevalence of diabetes in women in Jamaica, ${ }^{11,31}$ but may also reflect gender differences in health-seeking behavior. This may limit our ability to generalize to all men in the Jamaican community, but still represents our best estimate of the burden of CVD among men with diabetes. No conclusions can be drawn from the finding of an association between cerebrovascular disease and participants with unknown HDL, but this suggests the need for further research in this area.

Although the study was conducted in a specialist diabetes clinic, we note that the estimated prevalence of heart attack and stroke were generally similar to that among persons with diabetes in the general population of Jamaica, ${ }^{11}$ therefore implying that the findings may be generalizable to the population of persons with diabetes in Jamaica and possibly to other black populations of similar age and diabetes duration.

It is also important to note that the findings in this study represent only persons who have had nonfatal CVD, and will therefore underestimate the full impact of CVD among persons with diabetes. Additionally, some of the significant associations may be factors associated with survival with CVD and not necessarily the factors associated with incident CVD. This supports the need for more prospective studies of diabetes complications in black populations living in countries undergoing epidemiological transition.

This study is the first to report on the prevalence of CVD and its risk factors among patients attending diabetes clinics in Jamaica, and reiterates the need for CVD prevention and control among persons with diabetes and the importance of addressing CVD as part of any patient diabetes education intervention. We are unaware of any other studies from developing countries which have examined this issue in a predominantly black population. In light of the World Health Organisation reports suggesting that approximately $80 \%$ of CVD deaths occur in developing countries, ${ }^{32}$ this study is an important addition to the literature in this field.

From our analyses, duration of diabetes had the strongest and most consistent association with CVD, suggesting that strategies for controlling CVD must include delaying the onset of diabetes. Additionally, it is critical that health care providers be more aggressive in their screening for symptoms of coronary disease among older patients with longstanding diabetes as a means of secondary prevention of the consequences of this disorder. They should also have a high level of suspicion for coronary disease should these patients present to hospital. Ensuring adequate blood pressure control and encouraging increased physical activity should also be a part of the strategy for CVD reduction. Clinicians should screen annually for cardiovascular risk factors, as recommended by international and regional guidelines. ${ }^{33,34}$ Cardiac testing should be initiated in individuals with typical or atypical cardiac symptoms or an abnormal resting electrocardiogram, as recommended by the American Diabetes Association, ${ }^{34}$ and efforts to increase patients' access to these services should be encouraged. All patients with diabetes should have some assessment performed to determine their cardiovascular risk and should receive appropriate preventative measures. ${ }^{34,35}$ The high prevalence of established disease in this population with diabetes also points to the need for aggressive secondary and tertiary prevention measures for patients who are at very high risk for recurrent cardiovascular events and significant morbidity from the disease. Governments should consider a greater subsidy for cardiovascular medications and services for patients with diabetes as one means of stemming this epidemic. Educational programs for patients with diabetes must include a significant CVD prevention component, and should include strategies for behavior change which will enhance interventions for primary and secondary prevention of CVD.

\section{Conclusion}

Approximately $35 \%$ of patients with diabetes mellitus in this tertiary care setting had at least one CVD. CVD prevalence is associated with age, diabetes duration, and uncontrolled hypertension and is more common among the physically inactive. Physicians should ensure that CVD risk reduction strategies are incorporated in the care of patients with diabetes.

\section{Acknowledgments}

The authors thank the study participants, project staff (including nurses C Bennett, B Walker, and R Walters), administrative staff (N Campbell), and our driver (J Campbell) for their contribution to the project. This study was supported by a grant from the Caribbean Health Research Council. The authors also thank UWI Medical Alumnus, Dr Earl O’Brien, and the National Health Fund (Jamaica) for assistance with equipment for the project.

\section{Disclosure}

The authors report no conflicts of interest in this work. 


\section{References}

1. Third Report of the National Cholesterol Education Program (NCEP) Expert Panel on Detection, Evaluation, and Treatment of High Blood Cholesterol in Adults (Adult Treatment Panel III) Final Report. Circulation. 2002;106(25):3143-3421.

2. Grundy SM, Benjamin IJ, Burke GL, et al. Diabetes and cardiovascular disease: A statement for healthcare professionals from the American Heart Association. Circulation. 1999;100(10):1134-1146.

3. Beckman JA, Creager MA, Libby P. Diabetes and atherosclerosis: Epidemiology, pathophysiology, and management. JAMA. 2002;287(19): 2570-2581.

4. Beckman JA, Libby P, Creager MA. Diabetes mellitus, the metabolic syndrome, and atherosclerotic vascular disease. In: Libby P, Bonow RO, Mann DL, Zipes DP, editors. Braunwald's Heart Disease. Philadelphia, PA: Saunders Elsevier; 2007.

5. American Diabetes Association. Standards of Medical Care in Diabetes - 2010. Diabetes Care. 2010;33 Suppl 1:S11-S61.

6. King H, Aubert RE, Herman WH. Global burden of diabetes, 1995-2025: Prevalence, numerical estimates, and projections. Diabetes Care. 1998;21(9):1414-1431.

7. Wild S, Roglic G, Green A, Sicree R, King H. Global prevalence of diabetes: Estimates for the year 2000 and projections for 2030. Diabetes Care. 2004;27(5):1047-1053.

8. Ferguson TS, Tulloch-Reid MK, Wilks RJ. The epidemiology of diabetes mellitus in Jamaica and the Caribbean. A historical review. West Indian Med J. 2010;59(3):259-264.

9. Miller GJ, Beckles GLA, Maude GH, et al. Ethnicity and other characteristics predictive of coronary heart disease in a developing community: Principal results of the St. James survey, Trinidad. Int J Epidemiol. 1989; 18(4):808-817.

10. Ferguson TS, Tulloch-Reid MK, Younger NO, et al. Cardiovascular disease among diabetic in-patients at a tertiary hospital in Jamaica. Diab Vas Dis Res. 2010;7(3):241-242.

11. Ferguson TS, Younger NO, Morgan ND, et al. Self-reported prevalence of heart attacks and strokes in Jamaica: A cross-sectional study. The Jamaica Health and Lifestyle Survey 2007-2008. Research Reports in Clinical Cardiology. 2010;1:23-31.

12. Gulliford MC, Mahabir D. Diabetic foot disease and foot care in a Caribbean community. Diabetes Res Clin Pract. 2002;56(1):35-40.

13. Alberti KG, Zimmet P, Shaw J. The metabolic syndrome - a new worldwide definition. Lancet. 2005;366(9491):1059-1062.

14. Ataman SL, Cooper R, Rotimi C, et al. Standardization of blood pressure measurement in an international comparative study. J Clin Epidemiol. 1996;49(8):869-877.

15. NycoCard HbA1c Test Fact Sheet. Available from: http://www.axisshield-poc.com/esite/esite.nsf/pub/MBOA7ZWFL8/\$file/MBOA7Z WFLY.pdf. Accessed January 1, 2011.

16. NycoCard HbA1c NGSP Certificate 2010-2011. Available from: http:// www.axis-shield-poc.com/esite/esite.nsf/pub/BLOH8AWH6B/\$file/ BLOH8AWH6E.pdf. Accessed January 1, 2011.

17. UKPDS Risk Engine. Available from: http://www.dtu.ox.ac.uk/risken gine/. Accessed January 1, 2011.

18. Centers for Disease Control and Prevention. Prevalence of selfreported cardiovascular disease among persons aged $\geq 35$ years with diabetes - United States, 1997-2005. MMWR Morb Mortal Wkly Rep. 2007;56(43):1129-1132.

Research Reports in Clinical Cardiology

\section{Publish your work in this journal}

Research Reports in Clinical Cardiology is an international, peer-reviewed, open access journal publishing original research, reports, editorials, reviews and commentaries on all areas of cardiology in the clinic and laboratory. The manuscript management system is completely online and includes a very quick and fair peer-review system.
19. Jurado J, Ybarra J, Solanas P, et al. Prevalence of cardiovascular disease and risk factors in a type 2 diabetic population of the North Catalonia diabetes study. J Am Acad Nurse Pract. 2009;21(3):140-148.

20. Intensive blood-glucose control with sulphonylureas or insulin compared with conventional treatment and risk of complications in patients with type 2 diabetes (UKPDS 33). Lancet. 1998;352(9131):837-853.

21. Gerstein HC, Miller ME, Byington RP, et al. Action to Control Cardiovascular Risk in Diabetes Study Group. Effects of intensive glucose lowering in type 2 diabetes. N Engl J Med. 2008;58(24):2545-2559.

22. Goff DC Jr, Gerstein HC, Ginsberg HN, et al. Prevention of cardiovascular disease in persons with type 2 diabetes mellitus: Current knowledge and rationale for the Action to Control Cardiovascular Risk in Diabetes (ACCORD) trial. Am J Cardiol. 2007;99(12A):4i-20i.

23. Engstad T, Bonaa KH, Viitanen M. Validity of self-reported stroke: The Tromso Study. Stroke. 2000;31(7):1602-1607.

24. Haapanen N, Miilunpalo S, Pasanen M, Oja P, Vuori I. Agreement between questionnaire data and medical records of chronic diseases in middle-aged and elderly Finnish men and women. Am J Epidemiol. 1997;145(8):762-769.

25. Okura Y, Urban LH, Mahoney DW, Jacobsen SJ, Rodeheffer RJ. Agreement between self-report questionnaires and medical record data was substantial for diabetes, hypertension, myocardial infarction and stroke but not for heart failure. J Clin Epidemiol. 2004;57(10):1096-1103.

26. Olsson L, Svardsudd K, Nilsson G, Ringqvist I, Tibblin G. Validity of a postal questionnaire with regard to the prevalence of myocardial infarction in a general population sample. Eur Heart J. 1989;10(11):1011-1016.

27. Walker MK, Whincup PH, Shaper AG, Lennon LT, Thomson AG. Validation of patient recall of doctor-diagnosed heart attack and stroke: A postal questionnaire and record review comparison. Am J Epidemiol. 1998;148(4):355-361.

28. Bergin S, Brand C, Colman P, Campbell D. A questionnaire for determining prevalence of diabetes related foot disease (Q-DFD): Construction and validation. J Foot Ankle Res. 2009;2(1):34.

29. Davis TME, Millns H, Stratton IM, Holman RR, Turner RC. UK Prospective Diabetes Study Group. Risk Factors for Stroke in Type 2 Diabetes Mellitus: United Kingdom Prospective Diabetes Study (UKPDS) 29. Arch Intern Med. 1999;159(10):1097-1103.

30. Turner RC, Millns H, Neil HAW, et al. Risk factors for coronary artery disease in non-insulin dependent diabetes mellitus: United Kingdom Prospective Diabetes Study (UKPDS: 23). BMJ. 1998;316(7134):823-828.

31. Wilks R, Younger N, Tulloch-Reid M, McFarlane S, Francis D. Jamaica Health and Lifestyle Survey 2007-8. Technical Report. 2008. Available from: http://www.mona.uwi.edu/reports/health/JHLSH_final_may 09.pdf. Accessed February 18, 2011.

32. World Health Organization. Cardiovascular disease: Prevention and control. Available from: www.who.int/dietphysicalactivity/ publications/facts/cvd/en/index.html. Accessed May 12, 2010.

33. Managing Diabetes in Primary Care in the Caribbean. Available from: http://www.chrc-caribbean.org/files/Guidelines/Diabetes\%20Guide lines.pdf. Accessed February 15, 2011.

34. American Diabetes Association. Standards of Medical Care in Diabetes - 2011. Diabetes Care. 2011;34 Suppl:S11-S61.

35. Mendis S, Lindholm LH, Mancia G, et al. World Health Organization (WHO) and International Society of Hypertension (ISH) risk prediction charts: Assessment of cardiovascular risk for prevention and control of cardiovascular disease in low and middle-income countries. J Hypertens. 2007;25(8):1578-1582.

\section{Dovepress}

Visit http://www.dovepress.com/testimonials.php to read real quotes from published authors. 